\title{
Chiropractic students' experiences on the use of virtual radiography simulation: a pilot observational study
}

\author{
Madeleine Shanahan', Tom Molyneux ${ }^{2}$ and Dein Vindigni ${ }^{*}$
}

\begin{abstract}
Background: Virtual radiography provides students with an opportunity to practise their clinical skills in patient positioning and evaluating radiographic images. The purpose of this pilot study was to introduce Projection VR ${ }^{\mathrm{TM}}$, a software radiography simulation program, into a student chiropractic program and evaluate its potential application as a teaching and learning tool.

Methods: Undergraduate chiropractic students, enrolled in a radiographic course (unit within the chiropractic program), were invited to attend a scheduled laboratory where they were introduced to, and undertook purposefully designed activities using the radiography simulation. At the end of this activity, students were asked to complete an online survey (see Virtual Radiography Survey) to describe their experiences of the educational value of the software program. Descriptive statistics were used to evaluate outcomes. Content analysis was performed for free-text comments provided by respondents with key themes provided by the predetermined quantitative categories of the questionnaire.
\end{abstract}

Results: Responses were received from 44 out of the 47 students who attended the scheduled laboratory (response rate 92\%). Overall students were positive about this simulation identifying that it was easy to use (95\%) and that they could control the equipment as needed (95\%). The main reported benefits included students being enabled to repeat tasks until they were satisfied with the results (98\%) and being able to quickly assess images and determine if changes needed to be made (98\%). Participants reported improvement in their understanding of the effect of exposure factors on patient radiation dose (93\%) as well as their technical image evaluation (84\%) and problem-solving skills (80\%).

Conclusions: The results of this study suggest that virtual radiography is a valuable complementary resource in providing chiropractic students with radiographic knowledge and skills.

Keywords: Chiropractors, Radiography, Simulation

\section{Background}

The World Federation of Chiropractic defines chiropractic as a health profession concerned with the diagnosis, treatment and prevention of mechanical disorders of the

\footnotetext{
* Correspondence: dein.vindigni@rmit.edu.au

${ }^{2}$ School of Health and Biomedical Sciences, RMIT University, Melbourne, Australia

Full list of author information is available at the end of the article
}

musculoskeletal system and the effects of these disorders on the function of the nervous system andAQ3 general health [1]. Radiography has been integrated into chiropractic teaching programs since 1910 when B.J. Palmer purchased an x-ray unit for the Palmer School of Chiropractic in Davenport, Iowa [2]. It has been used as a diagnostic tool in the biomechanical evaluation of the spine and

(c) The Author(s). 2021 Open Access This article is licensed under a Creative Commons Attribution 4.0 International License, which permits use, sharing, adaptation, distribution and reproduction in any medium or format, as long as you give appropriate credit to the original author(s) and the source, provide a link to the Creative Commons licence, and indicate if changes were made. The images or other third party material in this article are included in the article's Creative Commons licence, unless indicated otherwise in a credit line to the material. If material is not included in the article's Creative Commons licence and your intended use is not permitted by statutory regulation or exceeds the permitted use, you will need to obtain permission directly from the copyright holder. To view a copy of this licence, visit http://creativecommons.org/licenses/by/4.0/ The Creative Commons Public Domain Dedication waiver (http://creativecommons.org/publicdomain/zero/1.0/) applies to the data made available in this article, unless otherwise stated in a credit line to the data. 
pelvis and to help identify contraindications to manual therapy.

It continues to be taught as a core course in all chiropractic programs in Australia and most chiropractic programs throughout the world [3-5].

Maintaining the quality of imaging whilst minimising the radiation dose to patients is a priority which is highlighted by the Australian Radiation Protection and Nuclear Safety Agency [6] and one which is emphasised in clinical radiographic training and radiology courses (MEDS2144 Introduction to Diagnostic Imaging, MEDS2143 Advanced Diagnostic Imaging and REHA2203 Chiropractic 6 Theory) at RMIT University [7].

The opportunity to participate in simulated radiography complements rigorous training in the theoretical and clinical aspects of plain film diagnostic imaging. At the time of this pilot study, radiography was a subject in year four of the five-year chiropractic program. This was undertaken prior to the students performing supervised radiography in the teaching clinics in which students treat members of the public under the supervision of qualified chiropractors. Supervised radiography may be performed by the students as part of that experience. Students graduating from the chiropractic course are eligible to apply for a limited x-ray (Use) licence and so it is important that students have a sound understanding of the radiographic principles and practice that are related to the scope of practice of their limited $x$-ray licence.

In recent years, computer-based simulation radiography has been introduced in undergraduate radiography programs with promising results $[8,9]$. However, its usefulness in achieving clinical learning outcomes in pre-clinical undergraduate chiropractic programs has not been previously piloted and evaluated.

This pilot study aimed to introduce a software radiography simulation tool called Projection $\mathrm{VR}^{\mathrm{Tm}}$ into a chiropractic, pre-clinical undergraduate setting and gather student feedback about its application as a clinical learning tool and strategy. According to the literature, no other chiropractic institution or training program has implemented simulated radiography in their curriculum. Since completing this pilot study; however, literature has been published on the use of other virtual radiography software $[10,11]$. The Projection VR TM software has been well described by Shanahan [9].

\section{Methods}

The Human Research Ethics Committee of the Royal Melbourne Institute of Technology (RMIT) University
(BSEHAPP 06-15) approved the project, including its design and recruitment methods.

\section{Research design}

This descriptive study used an observational pilot to evaluate the impact of the software. In this pilot study, students had their first introduction to the Project VR TM software. As this was an initial implementation, we sought to obtain student quantitative and qualitative feedback as part of the evaluation process.

\section{Participants}

Chiropractic students in the second semester of year four of the program in 2016 were recruited as part of their traditional practical sessions in radiography. Informed consent was obtained in the first test item of an online survey (see Virtual Radiography Survey), with respondents able to exit at this point if they so preferred. Of a total of 113 students enrolled in the subject, only the first 20 in each of five groups were given the opportunity to participate. We used a convenience selfselection method to recruit the participants, forty four students voluntarily responded to the survey questions. Students involved in this pilot study had already spent 11 weeks of a 12-week semester with the radiography tutor.

\section{Procedure}

Participating chiropractic students were scheduled to attend one laboratory session which used the computerbased virtual radiography simulation software Projection $\mathrm{VR}^{\mathrm{Tm}}$. Projection $\mathrm{VR}^{\mathrm{Tm}}$ simulation in this university setting could be adequately delivered via Windows 8 or 7 (64 or 32 bit) with a graphics processor of at least DirectX and Shader Model 3.0 or 4.0 hardware support and 512 megabytes or more of dedicated video RAM. The standard computer laboratory equipment at the university met or exceeded these requirements.

A worksheet on simulated radiography of the lumbar spine was developed for chiropractic students using Projection $\mathrm{VR}^{\mathrm{m}}$. The lumbar spine was chosen as it represents one of the most common areas that chiropractors request radiography for. In a research paper by Metaxas (2018), the seven most common areas to be $\mathrm{x}$-rayed included the lumbar spine and pelvis. No training was conducted prior to using the simulated radiography system as students learned to use the technology while they undertook the activity under the guidance of an experienced lecturer in radiography [12]. The detailed worksheet allowed the students to use the technology as they undertook the laboratory activity. Each student used the simulation individually.

There were three key areas of focus for this activity. Firstly, for each student to simulate patient positioning 
and technical set up in preparation for taking the Anterior to Posterior lumbopelvic image and to generate an AP lumbopelvic (APLP) image (Fig. 1). Secondly, having produced an unrotated APLP, students were then asked to rotate their patient so that the patient's right posterior side was closer to the image receptor (Fig. 2). Before generating the image, students were asked what distinguishing anatomical features they expected to see on the image (Fig. 2). This strategy was used to support active and engage critical thinking as students consciously paused and reflected before they undertook their next action [13]. Thirdly, the effect of exposure factor selection on the digital image as well as patient dose was investigated. This was tested using two methods, namely application of the $15 \%$ rule and the effect of decreasing and increasing milliamp seconds (mAs) on digital images. Increasing kilovolt peak $(\mathrm{kVp})$ with a concomitant decrease in $\mathrm{mAs}$ is expressed as the $15 \% \mathrm{kVp}$ rule. The $15 \%$ rule states that a $15 \%$ increase in $\mathrm{kVp}$ is the equivalent of doubling the exposure received at the image receptor $[14,15]$. To maintain exposure at the image receptor, the $\mathrm{mAs}$ is halved. The increase in $\mathrm{kVp}$, when applying the $15 \%$ rule, is variable and dependent on the original $\mathrm{kVp}$. For example, at $60 \mathrm{kVp}$, the calculated change in $\mathrm{kVp}$ would be $9 \mathrm{kVp}$ whereas at $80 \mathrm{kVp}$, the required change would be $12 \mathrm{kVp}$. Studies examining application of the $15 \% \mathrm{kVp}$ rule have demonstrated a considerable reduction in patient dose (22-60\%) without adversely affecting image quality $[16,17]$. This is an important finding as increasing $\mathrm{kVp}$ reduces subject contrast and could therefore potentially negatively impact image quality $[14,15]$. Before generating the image acquired using the $15 \%$ rule, students were asked what change if any they may expect to see on the image
(Fig. 3) and what impact, if any, applying the $15 \%$ rule would have on patient dose. Technical data available in Projection VR ${ }^{\mathrm{Tw}}$ relating to radiation dose for the two images generated is provided in Fig. 4. Entrance surface dose (ESD) measurements were compared for the two exposure techniques. The final aspect of selection of exposure factors on digital images was undertaken by asking students what difference they would expect to see on the radiographic image and on patient dose if they were to half or double the mAs. Generated images are provided in Fig. 5.

Throughout the session, students were asked to predict the outcome of each change in patient position or exposure factors before they generated and saw images or technical data. This method was used to encourage students to think critically in applying their decisionmaking skills in a clinical setting and has been found to reinforce learning by other authors $[13,18,19]$.

\section{Data analysis}

The survey data were entered into SPSS $21.0^{\circ}$ and descriptive statistics were used for analysis. Analysis of survey data was descriptive only as this research involved an exploratory snap-shot process - that is, the survey was only administered once [20] .

\section{Results}

Responses were received from 44 out of 47 participants in the practical sessions. The sex and age characteristics of the responding students are presented in Table 1.

The majority of students were female $(68 \%)(\mathrm{M}=14, \mathrm{~F}=$ 30). All age groups were represented in this sample and included both high school leavers and mature aged students.

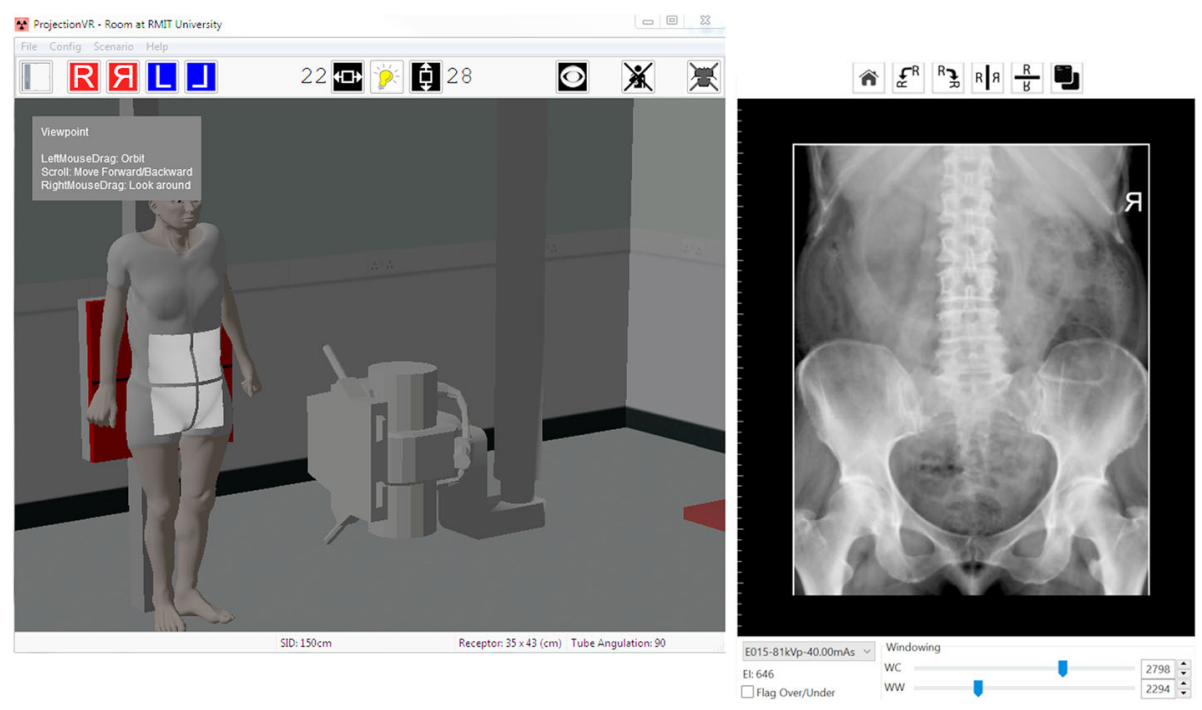

Fig. 1 Technical set up for Anterior to Posterior lumbopelvic (left) and resultant image generated (right) using Projection VR ${ }^{\mathrm{TM}}$ 


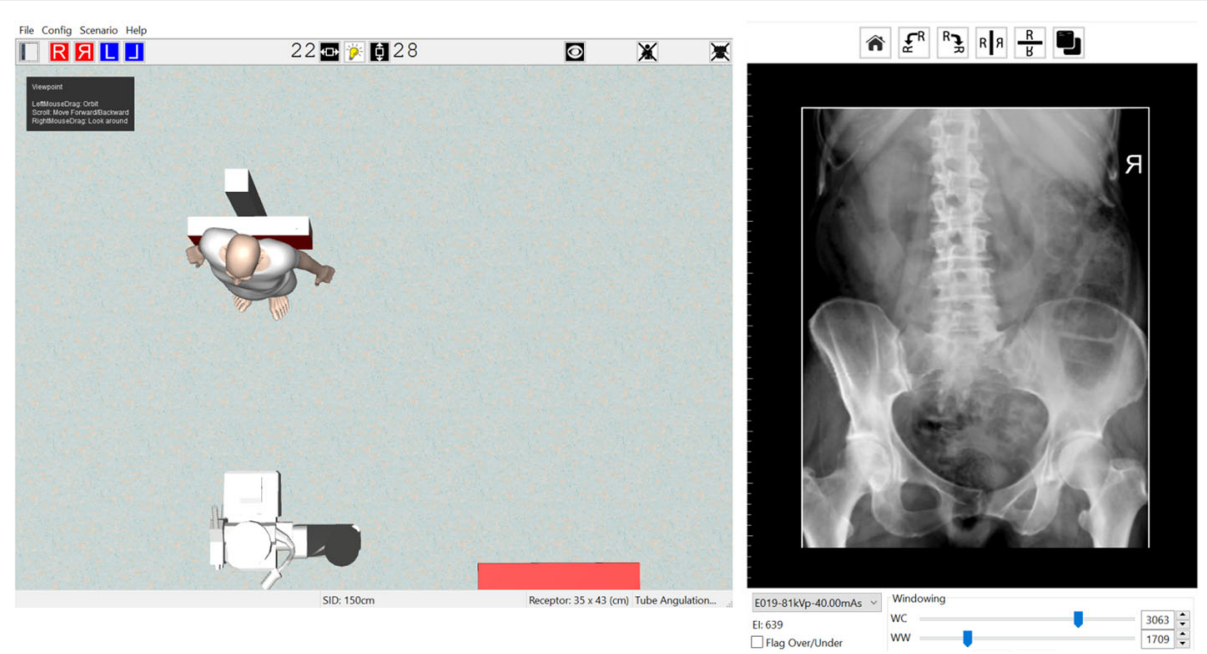

Fig. 2 Technical set up for rotated (Right anterior oblique position) Anterior to Posterior lumbopelvic (left) and resultant image generated (right) using Projection $\mathrm{VR}^{\mathrm{TM}}$

\section{Technology}

Given that Projection VR ${ }^{\mathrm{mi}}$ involves computer-based simulation, participants were asked about their confidence in using this technology as part of their learning strategy. Eighty-two\% $(n=36)$ of responding participants described themselves as confident or moderately confident in the use of computer technology. Only 18\% (eight students) reported that they had previous experience using computer- based simulation. Students' experiences of ease of use of Projection $\mathrm{VR}^{\mathrm{m} \mathrm{m}}$ are summarised in Table 2.

\section{Qualitative feedback of students' experiences of using projection $\mathrm{VR}^{\mathrm{TM}}$}

Content analysis was performed for free-text comments provided by respondents with key themes provided by the predetermined quantitative categories of

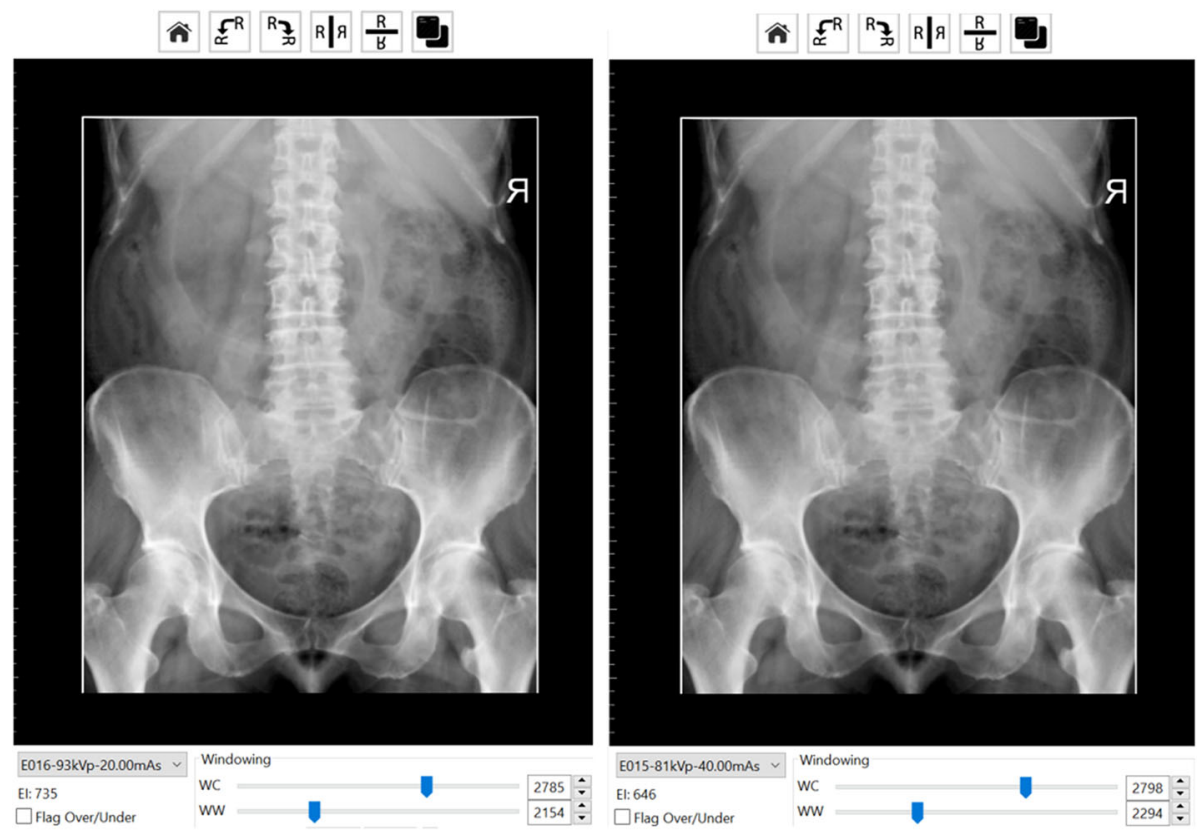

Fig. 3 Images generated using Projection VR ${ }^{\text {TM }}$ with 15\% rule applied. Image on right 81 kVp, 40 mAs and image on left 93 kVp, 20 mAs 


\section{E016-93kVp-20.00mAs}

Patient:Simpson^^Marjorie^ ${ }^{\wedge}$ Jacqueline ${ }^{\wedge}$ Mrs

Cassette:35CMX43CM

Tube Voltage: $93 \mathrm{kV}$

Care Filter: Off $(0.00 \mathrm{~mm} \mathrm{Cu})$

Tube Charge: $20.00 \mathrm{mAs}$

SID: $150 \mathrm{~cm}$

Coll: $22 \mathrm{~cm} \times 28 \mathrm{~cm}$ (@ $100 \mathrm{~cm}$ )

Part Thickness (CR): 263mm

Part Thickness: 225mm

Scatter Rej. Grid: Bucky 12:1

Scatter Fraction: 0.39

DAP: $158.01 \mathrm{cGy} \mathrm{cm}^{2}$

Incident Dose: $1.617 \mathrm{mGy}$

ESD: $2.313 \mathrm{mGy}$

Sys Dose(ROI): 6.24 uGy

Sys Dose(CR): 4.17 uGy

Sys Dose: 5.42 uGy

EI: 735

Agfa lgM: 2.43

Kodak P: 1925

Fuji S: 323

Fuji L: 1.38

\section{E015-81kVp-40.00mAs}

Patient:Simpson^^Marjorie^ ${ }^{\wedge}$ Jacqueline ${ }^{\wedge}$ Mrs

Cassette:35CMX43CM

Tube Voltage: $81 \mathrm{kV}$

Care Filter: Off $(0.00 \mathrm{~mm} \mathrm{Cu})$

Tube Charge: 40.00 mAs

SID: $150 \mathrm{~cm}$

Coll: $22 \mathrm{~cm}$ x 28cm (@ $100 \mathrm{~cm}$ )

Part Thickness (CR): 263mm

Part Thickness: 225mm

Scatter Rej. Grid: Bucky 12:1

Scatter Fraction: 0.37

DAP: 250.40 cGy $\mathrm{cm}^{2}$

Incident Dose: 2.553 mGy

ESD: $3.588 \mathrm{mGy}$

Sys Dose(ROI): 6.69 uGy

Sys Dose(CR): 4.17 uGy

Sys Dose: 5.61 uGy

EI: 646

Agfa lgM: 2.37

Kodak P: 1869

Fuji S: 312

Fuji L: 1.49

Fig. 4 Technical data display available when using Projection VRTM allowing for comparison of Entrance Surface Dose (ESD) with 15\% rule applied. Image on right 81 kVp, 40 mAs and image on left 93 kVp, 20 mAs

the questionnaire. Four themes emerged: ease of use of the simulation, learning using the simulation, limitations of the simulation, and recommendations for future implementation.
Ease of use of the simulation

Students were positive regarding ease of use of the simulation software and their ability to control the equipment during the learning activity. Some 

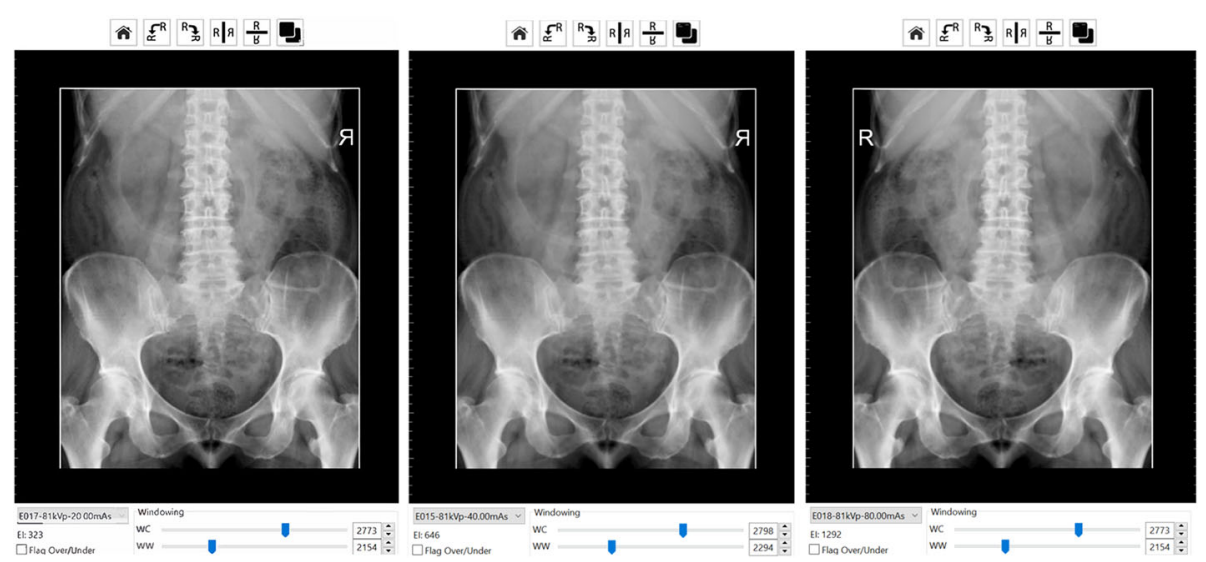

Fig. 5 Images generated using Projection $V R^{T M}$ at $81 \mathrm{kVp}$ and varying mAs $20 \mathrm{mAs}$ (left), $40 \mathrm{mAs}$ (centre) and $80 \mathrm{mAs}$ (right)

students commented that the simulation could be improved by making it easier to use, with one student specifying "some of the keys made it hard to set up accurately".

\section{Learning using the simulation}

Students generally considered Projection $\mathrm{VR}^{\mathrm{Tm}}$ as a worthwhile educational tool that quickly generated radiographic images and enabled them to refine the process until they were confident in its application. Student comments described benefits of using the simulation including "Easy and quick visualisation of an x-ray image", "It was a good simulation to be able to see what we're actually imaging" and "you can visualise anything you want to, at whatever angle you want to. Very helpful especially for visual learners like myself".

Students also reported that using the program encouraged them to think more about radiographic technique and it facilitated their problem-solving skills. Student comments included "made me think about what I was doing", "helped me to think wisely on how the image should be produced" and "enabled me to produce images and see where I needed to correct myself to get a better image".

In addition, students identified that the simulation activity enhanced their understanding of technical factor selection and radiation dose. For example, students stated that using the simulation "helped me to understand the exposure", "helped me understand the technical side, not just positioning" and it "gave us extra information on patient dose and levels of radiation".

Students also described the use of this simulation program as enhancing their learning opportunities. Their comments included "it combines the theory and practical context taught during Chiropractic Theory 6 whilst introducing a new way of expanding our skills and knowledge through technology" and "regular practice sessions with the computers would be great to assist the physical learning". Students also recognised that this simulation provided a safe learning environment as it did not require the use of radiation "being able to redo and correct any mistakes without worry".

\section{Limitations of the simulation}

Students did report limitations of the simulation including that, as movement of $\mathrm{x}$-ray tube was controlled by computer keys, "some buttons are difficult to find" and "some of the keys made it hard to set up accurately". It was also noted that as you are unable to palpate the virtual patient "more bony landmarks on patient" were needed.

\section{Recommendations for future implementation}

Students in this study identified that remote access to this simulation would be a beneficial change, for example, 'simulation of practicals into computers makes practice easier and more accessible', 'make it readily available to practise at home' and 'use of it at home via RMIT website, lists of views required for exam so we can practice'.

\section{Discussion}

The aim of this study was to explore chiropractic students' experiences of the Projection $\mathrm{VR}^{\mathrm{TM}}$ to assist in developing their radiographic skills and confidence in a laboratory setting. This study suggested that the simulation did improve students' learning experience.

The Projection $\mathrm{VR}^{\mathrm{TM}}$ was previously incorporated into the Medical Imaging program in the School of Health and Biomedical Sciences (SHBS) at RMIT University with most technical complications being resolved by the time the simulation program was trialled with 
Table 1 Demographic characteristics of participants $(n=44)$

\begin{tabular}{lll}
\hline Characteristic & & Number (\%) \\
\hline Sex & Female & $30(68)$ \\
& Male & $14(32)$ \\
Age (years) & $18-21$ & $22(50)$ \\
& $22-25$ & $11(25)$ \\
& $26-29$ & $4(9)$ \\
& $30+$ & $7(16)$ \\
\hline
\end{tabular}

chiropractic students. In general, the program supported students' skill development and enhanced confidence levels.

Another potential application of this program is remote access by students. The advantages of such access include the flexible delivery of learning and teaching, overcoming geographical barriers in terms of travel as well as students being able to acquire skills and knowledge at their own pace [21].

Given that there is variety in the reported levels of confidence, computer skills and abilities among students, the option of their being able to progress through simulation activities at their own pace is likely to facilitate the learning experience.

\section{Confidence and skill development}

In general, the introduction of Projection $\mathrm{VR}^{\mathrm{Tm}}$ increased students' confidence in patient positioning procedures and their ability to evaluate radiographic images. It has been reported that enhancing students' clinical radiographic skills as they make the transition from their pre-clinical undergraduate education to clinical practice may help to alleviate the stress associated with this transition [22].

Having acquired the skills to confidently set up radiographic procedures and evaluate images, students have reported being able to better focus their energies on refining their communication and patientinteraction skills [23].

Students also described that participating in the Projection $\mathrm{VR}^{\mathrm{TM}}$ simulation positively influenced their ability to problem solve. These findings are consistent with other published reports that highlight the value of students critically reflecting on their perceived strengths and weaknesses as a step to solving future clinical challenges and contributing to a range of other important clinical and professional standards [24, 25].

Ninety-three percent of students identified that the simulation activity enhanced their understanding of the effect of changing radiographic exposure factors on patient dose. Chiropractors who perform radiography have a responsibility to select exposure parameters which minimise patient dose when producing clinically diagnostic images. Key x-ray parameters that a chiropractor controls and can manipulate for radiographic examinations include tube voltage $(\mathrm{kVp})$, tube current and time (mAs) and source to image distance (SID). As SID is traditionally fixed at $150 \mathrm{~cm}$ for chiropractic planar imaging [26], student chiropractors should develop a good understanding of $15 \%$ rule as a radiation dose reduction strategy. Projection $\mathrm{VR}^{\mathrm{Tm}}$ simulation does provide similar percent dose reduction measurements to direct dosimetry measurements when assessing application of the $15 \%$ rule [27]. Projection $\mathrm{VR}^{\mathrm{TM}}$ is a useful educational tool

Table 2 Students' experiences of ease of use of Projection VR ${ }^{\text {TM }}(n=44)$

\begin{tabular}{|c|c|c|c|c|c|c|}
\hline Question & $\begin{array}{l}\text { Strongly } \\
\text { agree }\end{array}$ & Agree & $\begin{array}{l}\text { Neither agree } \\
\text { nor disagree }\end{array}$ & $\begin{array}{l}\text { Dis- } \\
\text { agree }\end{array}$ & $\begin{array}{l}\text { Strongly } \\
\text { disagree }\end{array}$ & $\begin{array}{l}\text { Total } \\
\text { Number }\end{array}$ \\
\hline I could control the equipment as I needed when using Projection VRTM & 15 & 27 & 2 & 0 & 0 & 44 \\
\hline I liked using Projection VR ${ }^{\mathrm{TM}}$ & 17 & 22 & 4 & 1 & 0 & 44 \\
\hline Projection VR ${ }^{T M}$ is easy to use & 8 & 34 & 2 & 0 & 0 & 44 \\
\hline Technical problems made using Projection VR ${ }^{\mathrm{TM}}$ difficult & 4 & 6 & 11 & 14 & 9 & 44 \\
\hline The Projection VRT⿳亠口冋 laboratory activity sheet was easy to follow & 7 & 29 & 7 & 1 & 0 & 44 \\
\hline \multicolumn{7}{|l|}{ Using Projection VR ${ }^{\mathrm{TM}}$} \\
\hline Encouraged me to think more about radiographic procedures & 17 & 22 & 3 & 2 & 0 & 44 \\
\hline Had a positive effect on my ability to set up a radiographic examination & 15 & 17 & 8 & 3 & 1 & 44 \\
\hline $\begin{array}{l}\text { Allowed me to quickly see images and understand if changes needed to be } \\
\text { made }\end{array}$ & 25 & 18 & 1 & 0 & 0 & 44 \\
\hline Had a positive effect on my ability to evaluate radiographic images & 17 & 20 & 7 & 0 & 0 & 44 \\
\hline $\begin{array}{l}\text { Helped me learn as I was able to repeat activities until I was satisfied with the } \\
\text { results }\end{array}$ & 21 & 22 & 1 & 0 & 0 & 44 \\
\hline Encouraged me to solve problems & 12 & 23 & 8 & 1 & 0 & 44 \\
\hline
\end{tabular}


to support student learning focussed on exposure parameters and dose reduction technique in planar radiography. Potential applications of the simulation program within the chiropractic curriculum may include:

a) assist in providing a blended learning approach to teaching radiographic positioning that includes the theoretical basis of radiography in chiropractic practice, face-to-face practicals and virtual radiography to complement and reinforce these more traditional approaches to teaching and learning;

b) help students to better understand how positioning influences radiation exposure (including factors such as skin dose and absorbed dose);

c) provide a cost-effective and efficient mechanism to 'practice' positioning;

d) assist in demonstrating how positioning influences radiographic anatomy;

e) currently, none of the four chiropractic programs in Australia incorporate virtual radiography in their curricula and the preliminary findings of this study demonstrate the potential to incorporate virtual chiropractic radiography into their curricula as part of an effective blended learning approach to learning and teaching.

More broadly, Projection VR TM may be a valuable adjunct to health professionals who with suitable radiographic training may operate diagnostic $\mathrm{x}$-ray equipment, as an example, due to large geographic distances, radiographic services in remote areas in Australia are often provided by appropriately trained remote $\mathrm{x}$-ray operators who include nurses, general practitioners and physiotherapists [28]. Remote access to this simulation supported by purposefully designed learning activities may enhance knowledge and skill development for remote $\mathrm{x}$-ray operators in areas relevant to their radiographic scope of practice.

\section{Study limitations}

This study explored the students' experiences of virtual radiography in the undergraduate pre-clinical radiography course as part of a university chiropractic program.

Due to the small sample size associated with this pilot study, caution should be adopted in interpreting and generalising the results. It is recommended that the study be repeated with an increased sample size to improve the generalisability of the findings. In addition, this study focussed on the lumbar spine, an area of current radiographic scope of practice for chiropractors. It is recommended that future research extend the areas of radiographic practice utilised with this simulation. It is also recommended that future research be extended to include the views of educators.

Previous authors have noted that student performance may be influenced by a variety of factors $[8,23]$ and this interplay of factors may confound the ability to independently evaluate the role of specific potential enablers such as simulated teaching. This is particularly true when an innovative teaching tool or strategy is introduced into a new learning environment [23].

Future research could examine student usage patterns of innovative teaching programs such as simulated radiography providing valuable information on how to best achieve flexibly-delivered clinical education programs such as this.

\section{Conclusion}

The Projection $\mathrm{VR}^{\mathrm{m}}$ software was adapted for use in an undergraduate university chiropractic radiography program.

The introduction of this software was associated with multiple benefits including an increase in skills and confidence in students' ability to effectively prepare their patients for radiographic positioning and quality imaging while minimising their exposure to irradiation dose.

The software also promoted their problem-solving skills in preparation for their transition to professional practice.

The results of this pilot study are promising and suggest that more extensive testing of the impact of simulated radiography with larger sample sizes and involving a number of chiropractic institutions be considered for further investigation.

Abbreviations

RMIT: Royal Melbourne Institute of Technology; SHBS: School of Health and Biomedical Sciences

\section{Supplementary Information}

The online version contains supplementary material available at https://doi. org/10.1186/s12909-021-02827-0.

Additional file 1. (Virtual Radiographic Chiropractic). (Survey to describe Chiropractic students' experiences on the use of virtual radiography simulation: A pilot observational study).

\section{Acknowledgements}

Thanks to Dr. Joe Messina and Mr. Bruno Treglia for supervising the students in the radiography lab and to all the chiropractic students who responded to our survey. Also, to Associate Professor Cliff Da Costa for his assistance in the statistical analysis and Dr. Andisheh Bastani for her help in formatting the manuscript.

\section{Authors' contributions}

Author MS originally developed, delivered and evaluated a virtual radiography program for use by radiography students and collaborated with TM and DV to adapt the radiography teaching tool for chiropractic students. Authors TM and DV helped in constructing variables and questions of particular relevance for chiropractic educators and students. Authors MS, TM and DV each assisted in analysing and interpreting the patient data, writing 
and editing the manuscript. All authors read and approved the final manuscript.

\section{Authors' information}

MSSchool of Health Sciences, University of Canberra. madeleine. shanahan@canberra.edu.au and Adjunct Associate Professor, School of Health and Biomedical Sciences, RMIT University.

TMDiscipline of Chiropractic, School of Health and Biomedical Sciences, RMIT University. tom.molymeux@rmit.edu.au

DVDiscipline of Chiropractic, School of Health and Biomedical Sciences, RMIT University. dein.vindigni@rmit.edu.au

\section{Funding}

This study was unfunded.

\section{Availability of data and materials}

The datasets used and/or analysed during the current study are available from the corresponding author on reasonable request.

\section{Declarations}

None.

\section{Ethics approval and consent to participate}

The project, including its design and recruitment methods was approved by the Human Research Ethics Committee of the Royal Melbourne Institute of Technology (RMIT) University (BSEHAPP 06-15). Informed consent was implied by completion and submission of the anonymous survey.

\section{Consent for publication}

Not applicable.

\section{Competing interests}

All authors declare they have no competing interests.

\section{Author details}

${ }^{1}$ School of Health Sciences, Faculty of Health, University of Canberra, Canberra, Australia. ${ }^{2}$ School of Health and Biomedical Sciences, RMIT University, Melbourne, Australia.

Received: 24 September 2020 Accepted: 13 July 2021

Published online: 28 July 2021

\section{References}

1. Peterson D, Wiese G. Chiropractic: An illustrated history. 1st ed ed. Mosby Incorporated; 1995.

2. The Council on Chiropractic Education. CCE Accreditation Standards 2018 In: Council on Chiropractic Education Australasia. http://www.cce-usa.org/ uploads/1/0/6/5/106500339/2018_cce_accreditation_standards.pdf. Accessed 24 June 2020.

3. Council on Chiropractic Education Australasia. Chiropractic Accreditation and Competency Standards 2017. In: Council on Chiropractic Education Australasia; 2017. https://www.ccea.com.au/files/1015/0450/1916/CCEA_A ccreditation_and_Competency_Standards_2017.pdf. Accessed 24 June 2020

4. European Council on Chiropractic Education. Accreditation Procedures and Standards. 2018. http://www.cce-europe.com/downloads.html. Accessed 24 June 2020.

5. Australian Radiation Protection and Nuclear Safety Agency. Codes and standards applicable to sources. https://www.arpansa.gov.au/regulation-andlicensing/licensing/information-for-licence-holders/licence-conditions/a pplicable-codes-and-standards. Accessed 24 June 2020.

6. RMIT University. BP280 - Bachelor of Health Science/Bachelor of Applied Science (Chiropractic). http://www1.rmit.edu.au/programs/structure/bp2 80hsddausbu. Accessed 24 June 2020.

7. Cosson P,Willis R. Comparison of student radiographers' performance in a real $\mathrm{x}$-ray room after training with a screen based computer simulator. 2012 http://www.shaderware.com/distrib/etc/WhitePaper-Compa risonOfStudentRadiographersPerformancelnaRealXrayRoomAfterTra iningWithAScreenBasedComputerSimulator.pdf. Accessed 24 June 2020.

8. Shanahan M. Student perspective on using a virtual radiography simulation. J Radiography. 2016;22(3):217-22.
9. Gunn $T$, Jones $L$, Bridge $P$, Rowntree $P$, Nissen $L$. The use of virtual reality simulation to improve technical skill in the undergraduate medical imaging student. J Interactive Learn Environ. 2018;26(5):613-20.

10. O'Connor M, Stowe J, Potocnik J, Giannotti N, Murphy S, Rainford L. 3D virtual reality simulation in radiography education: The students' experience. J Radiography. 2021;27(1):208-14.

11. Metaxas VI, Messaris GA, Lekatou AN, Petsas TG, Panayiotakis G. Patient doses in common diagnostic X-ray examinations. Radiat Prot Dosimetry. 2019;184(1):12-27.

12. Rodgers C. Defining reflection: Another look at John Dewey and reflective thinking. J Teach Col Record. 2002;104(4):842-66.

13. Bushong SC. Radiologic science for technologists-E-book: physics, biology, and protection. 10th ed. Elsevier Health Sciences; 2013.

14. Carlton RR, Adler AM. Principles of Radiographic Imaging. 5th ed. Cengage Learning; 2012.

15. Allen E, Hogg P, Ma WK, Szczepura K. Fact or fiction: an analysis of the 10 kVp 'rule'in computed radiography. J Radiography. 2013;19(3):223-7.

16. Lança L, Franco L, Ahmed A, Harderwijk M, Marti C, Nasir S, et al. 10 kVp rule-an anthropomorphic pelvis phantom imaging study using a $C R$ system: impact on image quality and effective dose using AEC and manual mode. J Radiography. 2014;20(4):333-8.

17. Jonassen $\mathrm{DH}$. Computers as mindtools for schools: Engaging critical thinking. 2nd ed. Prentice hall; 2000.

18. Jonassen DH. Meaningful learning with technology. 3rd ed. Upper Saddle River: Pearson/Merrill Prentice Hall; 2008

19. Lambert VA, Lambert CE. Qualitative descriptive research: An acceptable design. J Pac Rim Int J Nurs Res. 2012;16(4):255-6.

20. MacDonald-Hill J, Warren-Forward H. Feasibility study into the use of online instrumentation courses for medical radiation scientists. J Radiography. 2015:21(3):282-7.

21. Mason SL. Radiography student perceptions of clinical stressors. J Radio Technol. 2006;77(6):437-50.

22. Bridge $P$, Crowe S, Gibson G, Ellemor N, Hargrave C, Carmichael M. A virtual radiation therapy workflow training simulation. J Radiography. 2016;22(1): e59-63.

23. Kuiper RA, Pesut D. Promoting cognitive and metacognitive reflective reasoning skills in nursing practice: self-regulated learning theory. J Advanced Nurs. 2004:45(4):381-91.

24. Mann K, Gordon J, MacLeod A. Reflection and reflective practice in health professions education: a systematic review. J Adv Health Sci Educ. 2009; 14(4):595-621.

25. Yochum TR, Rowe LJ. Essentials of skeletal radiology. 2nd ed: Lippincott Williams \& Wilkins; 1987

26. Shanahan M. A pilot study investigating two dose reduction techniques for AP lumbar spine radiography using direct dosimetry and Projection VR. J Radiography. 2017;23(3):222-8.

27. Smith T, Fisher K. Self-reported competency and continuing education needs of limited licence remote $X$-ray operators in New South Wales, Australia. J Rural Remote Health. 2011;11(1):1560.

28. Definition of Chiropractic, world federation of Chiropractic. 2009. https:// www.wfc.org/website/index.php?option=com_content\&view=article\&id= 90\%20accessed\%2012\%20April\%202021. Accessed 1 May 2021.

\section{Publisher's Note}

Springer Nature remains neutral with regard to jurisdictional claims in published maps and institutional affiliations.

Ready to submit your research? Choose BMC and benefit from

- fast, convenient online submission

- thorough peer review by experienced researchers in your field

- rapid publication on acceptance

- support for research data, including large and complex data types

- gold Open Access which fosters wider collaboration and increased citations

- maximum visibility for your research: over $100 \mathrm{M}$ website views per year

At BMC, research is always in progress.

Learn more biomedcentral.com/submissions 